\title{
LA-6157-MS
}

Informal Report

\section{Cross Section Space Shielding in Doubly Heterogeneous HTGR Systems}

by

M. G. Stamatelatos
UC-77

Reporting Date: November 1975 Issued: November 1975 
In the interest of prompt distribution, this report was not edited by the Technical Information staff.

This work was supported by the Reactor Safety Research Division, US Nuclear Regulatory Commission.

Printed in the United Slates of America. Available from National Technical Informution Service

U S Department of Commerce S285 Port Royal Road

Price: Printed Copy \$4.00 Microtiche \$2 25

This report was prepared ot an account of work sponjored b. The Iinited Siates (iovernment. Neither the United Staten nor the United Stotes Enerzy Reserch end Development Admininiration, nor env of their employess, nor eny of their con warranty, excress or implied, or aseumes any lesal lis bilisy responnibility far the accuracy. completenesa. or unefulseas of env information. apperatus, product. or process disclosed, or represents thet its une would not infinge privately awned

rishls. 
CROSS SECTION SPACE SHIELDING

IN DOUBLY HETEROGENEOUS HTGR SYSTEMS

by

M. G. Stamatelatos

The report was preporice

spunswred by the Uniled Slates Goverount of work the United States not the Unutes suent Neithex

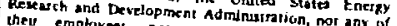
subrontrecturses. nat any of thes contractots warranty, expers of the ef employres, makes uny

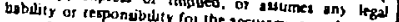
or uxfulnes of any intormetion, accuracy. completenes

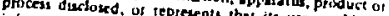
innge prostely outed resents that its use woult not

ABSTRACT

Collision probability methods using rational approximations far space shlelding of cross sections in nuclear reactor codes allowing for one level of heterogeneity are first reviewed. A Dancoff factor for a cylindrical HTGR fuel pin with grain structure is then derived. A new simple method for cross section space shielding in a doubly heterogeneous HTGR system using collision probabilities and rational approximations is subsequently presented tir: calculations based on $1 \mathrm{t}$ are compared with calculations based on more elaborate methods.

\section{INTRODUCTION}

Cross section space shlelding using collision probability methods and rational approximations for heterogeneous nuclear reactor systems have been in use for some time. Their virtue has been simplicity of application due to equivalence relations with homogeneous systems as well as good accuracy for most reactor calculations.

Recently, lifgh-Temperature Gas-Cooled Reactor (HTGR) systems, using a heterogeneous mixture of fuel gralns and moderator in the fuel rods, have been designed in the United States and abraad and the neut ronic calculations assoctated with such systems have required consideration of the "doubleheterogeneity" problom created by the geometry of such systems. Varfous nethods of varying degrees of difficulty in implementation have been proposed, 1-19 some of which have been incorporated in UTGK design calculations in the l'nited States and abroad.

Presented here is a simple method which can be incorporated in most multigroup cross section generation codes and which produces double-heterogeneity space shielding corrections to homogeneous neu$t$ ton cross sections that compare very well with results given by much more eiaborate methods.
II. COLLISION PROBABILITY METHODS AND RATIONAL APPROXIMATIONS

4. General Relations

Consider an array of fuel lumps in a homogeneous infinite moderator region. In order to calculate the escape probability ${ }^{\dagger}$ from all lumps, let us define the following quantities:

$P_{\text {esc }}$ - Escape probability from one fuel lump.

$P_{F, i}$ - Probability that a neutron incident on a fuel rod after i previous fuel traversals will collide in the fuel rod.

$\mathrm{P}_{\mathrm{M}, 1}$ - Probability that a neutron 1ncident on the moderator after $i$ prevlous fuel traversals w1ll collide in the moderator.

Then, the probability that a neutron will escape from all fuel lumps can be written as:

$$
\begin{aligned}
P_{\text {esc }}^{*} & =P_{\text {esc }}\left[P_{\mathrm{N}, 1}+\left(1-P_{M, 1}\right)\left(1-P_{F, 2}\right) P_{M, 2}\right. \\
& +\left(1-P_{M, 1}\right)\left(1-P_{F, 2}\right)\left(1-P_{M, 2}\right)\left(1-P_{F, 3}\right) P_{M, 3} \\
& +\ldots]
\end{aligned}
$$

\footnotetext{
The derivation Included here is similar to that given by Bell and Glasstone (Ref. 20).
} 
The various values of $P_{F, i}$ and $P_{M, i}$ are not $e-$ qual, but it is customary to approximate all $\mathrm{P}_{\mathrm{F}, i}$ by an average value $P_{F}$ and all $P_{M, 1}$ by an average value $P_{M}$. Consequently, we can approximate $P_{\text {esc }}^{*}$ in Eq. (1) by

$$
\begin{aligned}
P_{\text {esc }}^{*} & =P_{\text {esc }}\left[P_{M}+\left(1-P_{M}\right)\left(1-P_{F}\right) P_{M}+\ldots\right] \\
& =\frac{P_{\text {esc }} P_{M}}{1-\left(1-P_{M}\right)\left(1-P_{F}\right)}
\end{aligned}
$$

where

$$
1-P_{M}=C,
$$

$C$ being the usual Dancoff correction. Then $P_{\text {esc }}^{*}$ can be written as

$$
P_{\text {esc }}^{\star}=P_{\text {esc }} \frac{1-C}{.1-C\left(1-P_{F}\right)}
$$

This expression is based on "first collision" probabllitles and is valid for an Int inite array of lumps of any shape and composition. For a regular lattice of fuel rods, the relationship between $P_{\text {esc }}$ and $P_{F}$, as well as the probabilities themselves, depends on lattice pitch, on the fuel rod shape and composition.

\section{B. Regular Array of Homogeneous Convex Lumps}

Case et al. ${ }^{21}$ have shown that, for a homogeneous convex gray lump, $P_{F}$ and $P_{\text {esc }}$ are related by the following expression

$$
P_{F}=\Sigma_{F} \bar{\chi}_{F} P_{\text {esc }}
$$

where $\Sigma_{F}$ is the total macroscoplc fuel lump cross section, and $\bar{l}_{F}$ is the mean fuel lump chordlength, i.e.,

$$
\bar{l}_{F}=\frac{4 V_{F}}{S_{F}}
$$

$v_{F}$ and $S_{F}$ being the volume and the surface area of the lump, respectively.

$$
\text { Inserting Eq. (5) Into (4) gives } P_{\text {esc }}^{\star} \text { in teras }
$$
of the unknown quantity $P_{\text {esc }}$

$$
P_{\text {esc }}^{*}=\frac{P_{\text {esc }}}{i+\frac{C}{1-C} \Sigma_{F}^{\bar{l}} F_{\text {esc }}} \quad
$$

Expressions for $P_{\text {esc }}$ for homogeneous fuel lumps of various geometries have been calculated by many investigators. ${ }^{21-23}$ on the other hand, wigner ${ }^{24}$ has proposeil a "rational" appraximation for $P_{\text {esc }}$ which is exact: only in the two limits as $\bar{l}_{F} \rightarrow 0$ and $\bar{l}_{F}+\infty$

$$
\mathrm{P}_{\mathrm{esc}}^{k}=\frac{1}{1+\Sigma_{F_{F}}} \text {. }
$$

Advantages of this form in calculating narrow resonance integrals will be seen later. Improved versions of rational approximations for $P$ were later proposed by Bell, 25,26 Levine, ${ }^{27}$ otter, ${ }^{28}$ Kelber, ${ }^{29,30}$ Leslle et al. ${ }^{31}$ and others. The form given by Levine 27 is

$$
P_{\text {esc }}=\frac{1}{1+\frac{\sum_{F} \bar{l}_{F}}{A}} \text {, }
$$

where A, known as the Levine (or Be11) factor, is dependent on the shape of the lump. To show this, let us find a rational approximation for $P_{\text {esc }}$ for a homogeneous spherlcal lump of radius $R$ and macroscopic total cross section $\Sigma_{F}$. The exact equation given by Case et al. ${ }^{21}$ is

$$
\mathrm{P}_{\text {esc }}^{\text {sphere }}=\frac{3}{8\left(R \Sigma_{F}\right)^{3}}
$$

$$
\therefore \quad \times\left[2\left(R \Sigma_{F}\right)^{2}-1+\left(1+2 R \Sigma_{F}\right) e^{-2 R \Sigma} F\right]
$$

and can be rewritten as

$$
\underset{\text { esc }}{\text { sphere }}=\frac{3}{x^{3}}\left[\frac{x^{2}}{2}-1+(1+x) e^{-x}\right]
$$

where

$$
X \equiv \frac{3}{2} \sum_{F} \bar{l}_{F}
$$

and $\bar{l}_{F}$ for a sphere is

$$
\bar{l}_{F}=\frac{4 v_{F}}{s_{F}}=\frac{4}{3} R \text {. }
$$


For $\mathrm{X} \ll 1$, a series expansion for $\mathrm{P}_{\text {esc }}^{\text {sphere }}$ yields

$$
\mathrm{P}_{\text {esc }}^{\text {sphere }}=1-\frac{3}{8} x+\frac{1}{10} x^{2} \ldots \text {, }
$$

for which a very good approximation is

$$
\underset{\text { esc }}{\text { Sphere }}=\frac{1}{1+\frac{3}{8} X}=\frac{1}{1+\frac{9}{16} \Sigma_{F_{F}^{l}}}
$$

Consequently, we find $16 / 9$ to be a good value of A to use in the rational form (9) for a spherical homogeneous fuel lump. Good approximations for all values of $\Sigma_{F} \bar{l}_{F}$ were given by otter ${ }^{28}$

$$
\begin{aligned}
& A_{\text {sphere }}= \frac{16}{9}-0.2625 F_{F} \bar{l}_{F}+0.0259\left(\sum_{F} \bar{l}_{F}\right)^{3} \\
&\left(0 \leqslant \sum_{F} \bar{l}_{F}<1.36\right) . \\
& A_{\text {sphere }}=1+1.09 \frac{1}{\sum_{F} \bar{l}_{F}}-0.591 \frac{1}{\left(\sum_{F} \bar{l}_{F}\right)^{2}} \\
&\left(1.36 \leqslant \Sigma_{F} \bar{l}_{F}<\infty\right) .
\end{aligned}
$$

We observe that, in general, A depends not onily on the fuel lump geometry, but also on energy. For small fuel grains, as used in an HTCR, however, it is easy to establish that Eq. (15) is an excellent approximation to Eq. (10).

If Eq. (9) is inserted into Eq. (7), it follows that

$$
P_{F}=\frac{1}{1+\frac{\Sigma_{F}}{\Sigma_{e}}}
$$

where $\Sigma_{e}$ is an "effective" macroscoplc cross section dependent only on geometric parameters

$$
\Sigma_{e}=\frac{(1-C) A}{l_{F}[1+C(\Lambda-1)]} .
$$

It should be noced that if $A$ is set equal to unity, one obtains the Wigner rational approximation for $\Sigma_{e}$ as given by Bel1 26

$$
\Sigma_{e}^{B e 11}=\frac{1-C}{\bar{l}_{F}} .
$$

Equations (19) and (20) are used in a varlety of computer codes (e.g., Refs. 32 and 33) for making heterogeneit corrections to homogeneous medium cross sectlons. This is possible because of a well-known "equivalence" theorem ${ }^{34}$ derived here, for convenience, in the one-speed approximation. ${ }^{\dagger}$

The collision rate in the fuel region of volume $v_{F}$ for neutrons of energy $E$ is $V_{F} \Sigma_{F}(E) \Phi_{F}$. It is the result of contributions from the moderator

$$
P_{M}(E) V_{M} \int_{E}^{E / \mu_{m M}} \frac{\sum_{m M^{\phi} M^{\phi}}\left(E^{\prime}\right)}{\left(1-\alpha_{m M}\right)} d E^{\prime},
$$

and from the fuel

$$
\begin{aligned}
& {\left[1-P_{F}(E)\right] v_{F} \int_{E}^{E / \alpha_{m F}} \frac{\Sigma_{m F^{\phi}}\left(E^{\prime}\right)}{\left(1-\alpha_{m F}\right) E^{\prime}} d E^{\prime}} \\
& +\int_{E}^{E / \alpha a \Sigma_{S F^{\phi} M^{\prime}}\left(E^{\prime}\right)} \frac{\left(1-\alpha_{a}\right) E^{\prime}}{\left(E^{\prime},\right.},
\end{aligned}
$$

or

$$
\begin{aligned}
& v_{F} \Sigma_{F}(E) \phi_{F}=\left(1-P_{F}\right) v_{F} \\
& \times\left\{\int_{E}^{E / \alpha_{m F}} \frac{\Sigma_{m F_{F}}}{\left(1-\alpha_{m F}\right) E^{\prime}} d E^{\prime}+\int_{E}^{E / \alpha_{a}} \frac{\Sigma_{S F^{\phi} F}}{\left(1-\alpha_{a}\right) E^{\prime}} d E^{\prime}\right\} \\
& +P_{M} V_{F} \int_{E}^{F / \alpha_{m M}} \frac{\Sigma_{m M^{\prime} M}}{\left(1-\alpha_{m M}\right) E^{\prime}} d E^{\prime}
\end{aligned}
$$

where $V_{M}$ and $V_{F}$ are the moderator and fuel volumes, respectively, and $P_{N i}$ and $P_{F}$ are collision probabilities as deftned above. The quantity $\alpha$ is given by

This derivation is similar to one given in Ref. 20 . 


$$
\alpha=\left(\frac{1-A}{1+A}\right)^{2}
$$

where $A$ is the scatterer mass number and subscripts $\mathrm{mF}, \mathrm{mM}$, and a refer to moderator material in the fuel region, in the moderator region, and the absorber, respectively. $\Sigma_{S F}$ is the scattering cross section in the fuel.

The general reciprocity theorem,

$$
\sum_{m K} V_{M} P_{M}=\sum_{F} V_{F} P_{F}
$$

can be used to eliminate $P_{M}$ in Eq. (21),

$$
\begin{aligned}
& { }_{F_{F}}{ }_{F}=\left(1-P_{F}\right) \\
& \times\left[\int_{E}^{E / \alpha_{a}} \frac{\Sigma_{S F^{\dagger} F}}{\left(1-\alpha_{a}\right) E^{\prime}} d E^{\prime}+\int_{E}^{E / \alpha_{m F}} \frac{\Sigma_{m F^{\dagger} F}}{\left(1-\alpha_{m F}\right) E^{\prime}} d E^{\prime}\right] \\
& +{ }^{\prime} E_{E} \Sigma_{F} \int_{E}^{E / c_{m M}} \frac{\phi_{M}}{\left(1-\alpha_{m M}\right) E^{\prime}} d E^{\prime} .
\end{aligned}
$$

Varfous approximations can be used for the fluxes in the moderator and in the fuel rod moderating material. According to the narrow resonance apprcximation (NR), these fluxes are replaced by the asymptotic value

$$
\varphi_{a s y}=\frac{1}{E^{\prime}} \text {, }
$$

which, when Inserted into Eq. (24), yields

$$
\begin{aligned}
& \qquad \Sigma_{F} \phi_{F}=\left(1-P_{F}\right) \int_{E}^{E / \alpha_{a}} \frac{\Sigma_{S F_{F} \phi_{F}}}{\left(1-\alpha_{a}\right) E^{\prime}} d E^{\prime} \\
& +\left[\Sigma_{m F}+P_{F}\left(\Sigma_{a F}+\Sigma_{S F}\right)\right] \frac{1}{E}, \\
& \text { where } \\
& \Sigma_{F}=\Sigma_{a F}+\Sigma_{S F}+\Sigma_{m F}
\end{aligned}
$$

is the total fuel cross section.
Inserting the rational approxination form of Eq. (18) for $P_{F}$ in Eq. (26) yields, after some algebra,

$$
\begin{aligned}
& \left(\Sigma_{F}+\Sigma_{e}\right) \phi_{F}(F)=\int_{E}^{E / \alpha_{a}} \frac{\Sigma_{S F^{\phi} F}}{\left(1-\alpha_{a}\right) E^{\prime}} d E^{\prime} \\
& +\left(\Sigma_{m F}+\Sigma_{e}\right) \frac{1}{E} .
\end{aligned}
$$

If the sum $\Sigma_{m F}+\Sigma_{e}$ in Eq. (28) is replaced by $\Sigma_{m}$, Eq. (28) becomes identical to the collision rate in a homogencous medium with moderator cross section $\Sigma_{m}$. This established the equivalence between a homogenized system and a heterogeneous system in the MR approx1mation.

This equivalence theorem has been used in a number of codes correcting homogenized cross sections for space shielding due to one level of heterogeneity.

In the Bondarenko formalism ${ }^{35}$ of multigrouping cross sections in the narrow resonance approximation, the epithermal weighting flux is given by

$$
\phi(E)=\frac{1}{\sigma_{t}(E)+\sigma_{0}} \text {. }
$$

where $\sigma_{t}(E)$ is the total microscopic cross section and $\sigma_{0}$ is an effective cross section accounting for the energy shlelding due to large absorber concentrations in a homogeneous mediuri. In this formalism, it is particularly easy to further correct for cross section space shielding when the fuel resonance escape probability can be written in the rational form of Eq. (18). Then, the weighting flux sfmply becomes

$$
\phi(E)=\frac{1}{\sigma_{t}(E)+\sigma_{0}+\sigma_{e}} \text {, }
$$

where

$$
\sigma_{\mathrm{e}}=\frac{\Sigma_{\mathrm{e}}}{N_{F}},
$$

and $N_{F}$ is the absorber concentration ta the fuel rod. $A$ better approximation for the weighting flux in a homogenized region is provided by the intermedlate resonance approximation according to which, in a composition independent approach, 


$$
\phi(E)=\frac{1}{\sigma_{a}(E)+\lambda_{s}(E)+\tau_{0}}
$$

where all microscopic cross sections are given per absorber atom.

For heterogeneous configurations and for heavy moderators (1ike carbon), Seghal and Goldstein ${ }^{36}$ have proposed a weighting flux

$$
\forall(E)=\frac{1}{\sigma_{a}(F)+\lambda_{s}(E)+k^{r} \sigma_{m, a}+\omega_{a} \sigma_{a}} \text {. }
$$

where subscript $m, a$ refers to moderator admixed in fuel.

Parameters 1, l., ard ,. are related by zranscendental equations which, in the unbroadened Brelthifger approximation without interference, ${ }^{36}$ are

and

$$
\begin{aligned}
& k=1-x_{k: i}^{(a m)}, \\
& 1=1-x_{k}^{(f)},
\end{aligned}
$$

$$
i=1-\left[1-z+\left(1 \cdot e_{n}\right)\right] x_{k \lambda i}^{(m)},
$$

where

$$
x_{k}^{(1)}=\frac{\arctan x_{k}^{(1)}}{x_{k, k}^{(1)}} \text {, }
$$

and

$$
\begin{aligned}
& x_{k \lambda)}^{(i)}=2 F_{r}\left(1-a_{1}\right) /\left["\left(z_{111}+a_{k \lambda l}\right)\right] \text {, } \\
& a_{k \lambda \nu}^{2}=1+\frac{\sigma_{0}}{k \sigma_{a m}+\lambda \sigma_{p}+\sigma_{c}}\left(\frac{\Gamma_{n}+\lambda r_{n}}{\Gamma}\right) .
\end{aligned}
$$

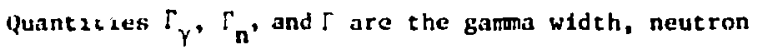
width, and total width of the resonance, respective1y. Superscripts am. F, and $m$ correspond to admixed moderator, resonance absorber, and outside muderator, respectively.

Using the empirical correlations of Sehgal 37

$$
\frac{1}{\lambda}=\left[1+\frac{2.2195}{R_{a}\left(\sigma_{0}\right)^{0.449}}\right]^{2} .
$$

where

$$
\begin{aligned}
& R_{a}=\frac{E_{r}\left(1-a_{a}\right)}{p}, \\
& \Gamma_{p}=\Gamma\left[\frac{\sigma_{1}}{\sigma_{p t h}+2 c_{p o x y}+\frac{N c}{N_{t h}} c_{c}+\frac{\bar{T}_{\mathrm{c}}}{\bar{X}_{t h}}}\right]^{\frac{1}{2}},
\end{aligned}
$$

and

$$
\frac{1}{k}=\left[1+\frac{2.2195}{R_{n}\left(r_{0}\right)^{0.449}}\right]^{2}
$$

where

$$
R_{m}=\frac{E_{r}\left(1 \cdot a_{m}\right)}{\Gamma_{p}},
$$

$\therefore$ Becker of Rensselaer Polytechnic Institute (RPI) inas est imated parameters; and $k$ for the important low-lying ${ }^{232}$ Th rescnance (at 23.4 el) in a graphite moderated system to be 0.92 and 0.996 , respectively. These results warrant the use of the NR approximation for the ${ }^{232}$ Th resonances in an HTGR systim, i.e., assuming $i$ and $k$ to both be equai to unisy.

c. Lnif orm Spherlcal-Grain Distribution in a Yoderator Macr $1 x$

Let us consider a unform distribution of equal siae spherical fuel grains in an in inite moderator medium. Equation (7) can then be writcen as

$$
P_{g}=P_{e} \frac{1-C_{0}}{1-C_{0}\left(1-\Sigma_{0} \bar{f}_{0} P_{e}\right)}
$$

there

$$
\begin{aligned}
& P_{g}=\text { escape probability frum all grains; } \\
& P_{0}=\text { escape probsbllity from one grain; } \\
& C_{0}=\text { grain-structure Dancoff factor; } \\
& \Sigma_{0}=\text { grain total macroscoplc cross section; } \\
& \bar{l}_{0}=\text { mean grain chordlength, } 1 . e . \frac{4 V_{0}}{S_{0}} ; \\
& V_{0}=\text { grain volume; } \\
& S_{0}=\text { grain surface area. }
\end{aligned}
$$


Using the rational approximation form of liq. (g) tor $P$

$$
P_{e}=\frac{1}{1+\frac{\bar{v}_{\overline{\bar{s}_{0}}}}{a}} \text {. }
$$

where a good energy-independent approxtmation ot it cor small grains is $16 / 9$ as discussed in Sec. Il-h. we obtain for $p_{g}$

$$
P_{B}=\frac{1}{1+\frac{E_{0}^{0}}{E_{e}^{0}}} \text {, }
$$

where

$$
\Sigma_{\mathrm{e}}^{0}=\frac{\left(1-c_{0}\right) \mathrm{a}}{i_{0}\left[1+\left(a-\frac{1}{\left.1) c_{0}\right]}\right.\right.} .
$$

The Dancoff facror $C_{0}$ for such an infinfte medfum was calculated by lane et $31 .^{6}$ to be

$$
c_{0}=\frac{1}{1+\frac{\overline{n_{0}^{N} D_{0}}}{1-f_{0}}} \text {, }
$$

where $\mathrm{K}_{0}, \mathrm{O}_{\mathrm{m}}$, and $\xi_{0}$ are the absorber density in the gri.ins, moderator cross section per absorber atom, and grain volume fraction, respectively.

III. DOUBLE HETEROGENEITY CORRECTIONS TO HONOGENEOUS CROSS SECTIONS THROLGH EQUIVALENCE RELATIONS

\section{General Expressions}

We now wh to simultaneously consider the tho levels of heterogenetty, the grain heterogenetty in the fuel rod, and the fuel pin heterogenefty in the reactor core, and to derive an overall absorber escape probability in terms of rational approximations. For this purpose, we will define the following avernge quunttties:

$P_{\text {e }}$ - escape probability from one grain;

$P_{n g}$ - probability that a neutron leaving a grain will not collide again with a grain in the same fuel pin;

$p_{E, 0}$ - probability that a neutzon incident on a fuel rod will re-emerge outside the rod elther uncollided or after any number of collisions in ti.e fuel-rod moderator;

$P_{Y}$ - probability that a neutron incident on the moderator outside a fuel pin will collide with It;

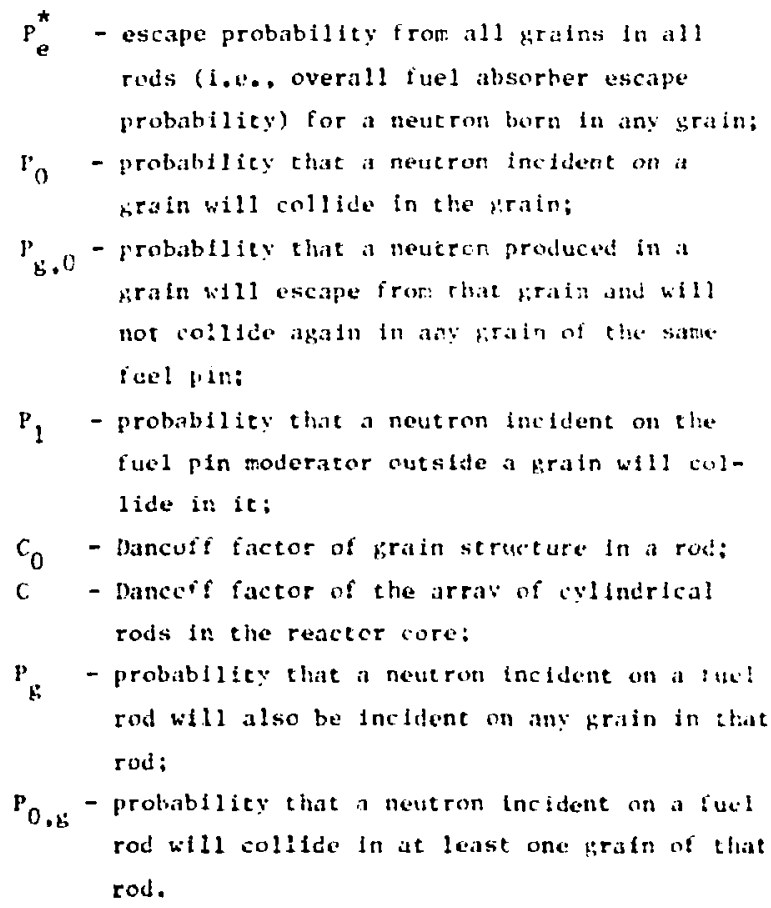

All gralne of the same cype are assumed to be of :qual size. Frotn these defintions, the following relat lons are obvlous

$$
\begin{aligned}
& c_{0}=1-p_{1} . \\
& c=1-P_{X} \quad \\
& P_{\mathrm{g}, \mathrm{C}}=\mathrm{P}_{\mathrm{e}} \mathrm{p}_{\mathrm{nt} ;}, \\
& P_{0, G}=P_{0} P_{g}, \\
& P_{f, 0}=1-P_{0, \xi} .
\end{aligned}
$$

Stace grains are assumed to have no structure, 1.e., are h.smogeneous, we also can write

$$
p_{0}=\Sigma_{0} \bar{r}_{0} p_{e}
$$

where $\Sigma_{0}$ is the total macroscoplc grain cross section and $\bar{\gamma}_{0}$ is the grain mean chordlength.

For a spherical grain of radius $R, \bar{t}_{0} 1 \mathrm{~s}$

$$
\bar{l}_{0}=\frac{4 V_{0}}{s_{0}}=\frac{4}{3} R \text {. }
$$

The overall grain escape probability $P_{e}^{*}$ is given by the sertes 


$$
\begin{aligned}
P_{e}^{*} & =P_{B, 0}\left[P_{M}+\left(1-P_{M}\right) P_{f, 0} P_{M}+\left(1-P_{M}\right)^{2} P_{f, 0}{ }^{2} P_{M}+\ldots\right] \\
& =P_{B, 0} \frac{P_{M}}{1-\left(1-P_{M}\right) P_{f, 0}}
\end{aligned}
$$

Substituting Eqs. (49) and (52) into Eq. (55), we obtain

$$
\mathrm{P}_{\mathrm{e}}^{*}=y_{\mathrm{g}, 0} \frac{1-\mathrm{C}}{1-\mathrm{C}\left(1-\mathrm{P}_{0, \mathrm{~g}}\right)} .
$$

ive can now relate $P_{g}$ and $P_{n g}$ through the reciprocity relation

$$
P_{g}=\frac{T_{B}}{T_{r g}}
$$

where $\bar{R}_{F}$ is the mean fuel rod chorulength and $\lambda_{g}$ is the geometric mean tree path of the grains 6

$$
h=\frac{1}{n \bar{r}_{0}} .
$$

where $n$ is the number of grains per unit volume and $\bar{\sigma}_{0}$ is the mean geometric cross section of one grain

$$
\bar{s}_{0}=\frac{s_{0}}{4} \text {. }
$$

$\because$ is the grain surface area and $n$ is given by

$$
n=\frac{t_{0}}{v_{c}} .
$$

where $f_{0}$ is the grains volume fraction in a fuel pin and $v_{0}$ the volume of one grain.

$$
\begin{aligned}
& \text { Then } \lambda_{g} \text { becomes } \\
& { }_{g}=\frac{v_{0}}{f_{0}} \frac{4}{s_{0}}=\frac{\bar{f}_{0}}{f_{0}},
\end{aligned}
$$

and $P_{B}$ of Eq. (57) becomes

$$
\mathrm{P}_{\mathrm{g}}=\mathfrak{q}_{0} \frac{\overline{\mathrm{r}}_{\mathrm{F}}}{\overline{\mathrm{R}}_{0}} \mathrm{p}_{\mathrm{ng}} \text {. }
$$

If Eqs. (50), (51), (53), and (62) are substituted into Eq. (56), one obtains

$$
\begin{aligned}
& P_{e}^{*}=\frac{P_{e}^{P} n g}{1+\frac{C}{1-c} \sum_{0} f_{0}^{\beta_{1}} F^{P} e_{n g}^{P}} \\
& =\frac{1}{\frac{1}{P_{e}^{P} n g}+\frac{C}{1-c} \sum_{0} f_{0} \bar{l}_{F}}
\end{aligned}
$$

Let us define $P_{C I}$ ae the first coll1sion probability anywhere in the fuel pin moderator outside the grains for neutrons escaping from a grain. The multiple collision probability $P_{n g}$ then becomes

$$
\mathrm{P}_{n \mathrm{~B}}=\mathrm{P}_{n C}+\left(1-\mathrm{P}_{n C}\right) \mathrm{P}_{C l}\left(1-\mathrm{P}_{0}\right) \mathrm{P}_{n C}
$$$$
+\left(1-P_{n C}\right)^{2} p_{C l}^{2}\left(1-P_{0}\right)^{2} P_{n C}+\ldots
$$$$
=\frac{P_{n C}}{1-\left(1-P_{n C}\right) P_{C 1}\left(1-P_{0}\right)}
$$

where

$$
\begin{aligned}
P_{C 1} & =P_{1}+\left(1-P_{1}\right)\left(1-P_{0}\right) P_{1} \\
& +\left(1-P_{1}\right)^{2}\left(1-P_{0}\right)^{2} P_{1}+\ldots \\
& =\frac{P_{1}}{1-\left(1-P_{1}\right)\left(1-P_{0}\right)}=\frac{1-C_{0}}{1-C_{0}\left(1-P_{0}\right)}
\end{aligned}
$$

and $P_{n C}$ is the no-collision probability for a neutron escaping from a grain.

Substituting Eq. (65) 1nto Eq. (64) gives

$$
P_{n g}=\frac{P_{n C}\left(1-C_{0}\left(1-P_{0}\right)\right)}{P_{0}+P_{n C}\left(1-P_{0}-C_{0}+P_{0} C_{0}\right)} \text {. }
$$

If Eqs. (66), (44), (53), and (63) are further combinid, one obtains

$$
\begin{aligned}
& \mathrm{P}_{\mathrm{e}}^{*}=
\end{aligned}
$$

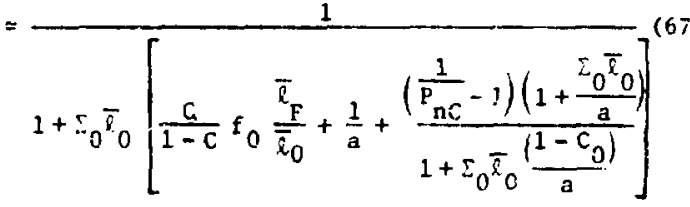

or alternately

$$
P_{e}^{*}=\frac{1}{1+\frac{\sigma_{k}}{\sigma_{\text {eff }}}}
$$

where

$$
\sigma_{\text {eff }}=-\frac{1}{N_{r} \bar{l}_{F}\left|\frac{C}{1-C}+\frac{1}{A^{*}}\right|}
$$

and

$$
\frac{1}{A^{*}}=\frac{\bar{l}_{0}}{\bar{l}_{F^{f}}} \cdot\left[\frac{1}{a}+\frac{\left(\frac{1}{\bar{P}_{n C}}-1\right)\left(1+\frac{\Sigma_{0} 0}{a}\right)}{1+\frac{\Sigma_{0} \bar{l}_{0}}{a}\left(1-c_{0}\right)}\right]
$$


and $\sigma_{F}$ is the fuel pin total microscopic cross section per absorber atom. It w111 be shown later that $\mathrm{P}_{\mathrm{nc}}$ and $\mathrm{C}_{0}$ are related through the following equation

$$
\mathrm{P}_{\mathrm{r} ; \mathrm{C}}=\frac{\bar{l}_{0}}{\mathrm{f}_{0} \bar{l}_{F}} \mathrm{C}_{0} \text {. }
$$

We now make a final approximation in the equation for $A^{*}$

$$
\Sigma_{0} \simeq \frac{1}{\lambda_{g}} .
$$

Then, we can write $A^{\star}$ as an approximately energyincependent quantity given by

$$
\frac{1}{A^{*}}=\frac{\bar{l}_{0}}{\bar{l}_{F} f_{0}}\left[\frac{\left(\frac{f_{0} \bar{l}_{F}}{\bar{l}_{0} c_{0}}-1\right)\left(1+\frac{f_{0}}{a}\right)}{1+\frac{f_{0}}{a}\left(1-c_{0}\right)}\right] .
$$

This implies that double hecerogeneity can be accounted for by simply replacing the Levine factor $A$ by the new factor $A^{*}$ in the single-heterczenelty space shielding correction. It should be noted that Eq. (69) Is identical with Eqs. (19) and (31) if $A^{*}$ replaces $A$.

Two problems yet unsolved are the calculation of $C_{0}$ and the accounting for scattering effects in the grains which usually contain absorber compounds with If ${ }^{3}$ ht elements, rather than pure fuel absorbers. These problems will be addressed next.

B. Dancoff Factor for Grain Structure in Infindte Cylindrisal Rods

The Dancoff factor given by $\mathrm{Eq}$. (4.7) was derived by Lane et $a 1 .{ }^{6}$ on the basis of a uniform chordlength distribution in an infinte medium. Wa will now remove this restriction and derive a Dancoff factor averaged over the chordlength distribution in an infinite cyifnder.

The Dancoff factor is defined as the probability that a neutron leaving an absorber lump will next collide in another absorber lump. In an infinite cylinder with grain structure, the Dancoff factor $c_{0}$ can be written as

$$
c_{0}=\int_{0}^{\infty} c_{0}(l) P(l) d l,
$$

where $P(l)$ is the chordlength distribution in the fuel rod, and $C_{0}(l)$ is the Dancof $\bar{r}$ factor along a specific chordlen; $c h$ in the cylinder. The actual chordlength distribution in an infinite cylinder as used by Case et al. ${ }^{21}$ is rather complicated, but Sauer ${ }^{38}$ has found that the following simplified distribution works quite well

$$
P(l) d \ell=\frac{1}{n !} u^{n} e^{-u} d u
$$

where

$$
u=\frac{(n+1) 2}{\bar{l}_{F}}
$$

Sauer has also found that a good value of $\mathrm{n}$ for ath infinfte cylinder is 3.58 . In view of the fact that $n$ is not an integer for the inf intte cylinder, the normalized distribution [Eq. (7s)] must be replaced by the following one

$$
P(\ell) d \ell=\frac{1}{\Gamma(n+1)} u^{n} e^{-u} d u
$$

because

$$
\int_{0}^{\infty} x^{m} e^{-a x} d x=\frac{\Gamma(m+1)}{a^{m+1}}
$$

where $\Gamma(m+1)$ is the gamma function.

Using the sarne train of thought as Lane et a1., we can now derive an expression for $\mathrm{C}_{0}(?)$. Let us flrst define $\lambda_{m}$ as the mean frec path for the fue! rod moderator outside the grains and $\lambda_{g}$ as the geometric mean free path for the grains

$$
\lambda_{m}=\frac{1}{N_{1} \sigma_{1}}
$$

and

$$
\lambda_{g}=\frac{1}{n_{\sigma_{0}}}
$$

where $N_{1} \sigma_{1}=\Sigma_{1}$ is the macroscopic cross section of the fuel rod moderator cutside the grains. Then $\mathrm{C}_{0}(l)$ can be written as

$$
C_{0}(\ell)=\int_{0}^{\ell} e^{-\Sigma r} \frac{d r}{\lambda_{g}}
$$


where

$$
\therefore=\frac{1}{\lambda_{m}}+\frac{1}{\lambda_{f}} .
$$

Integration of iq. (30) ylalds

$$
c_{0}(x)=\frac{1}{k^{5}}\left(1-e^{-2 \pi}\right) .
$$

or

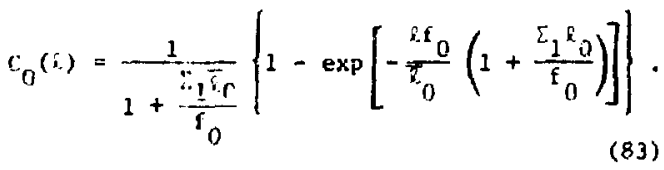

subst dtuting E45. (83) and (77) into E.q. (74) gives, after sone algebra

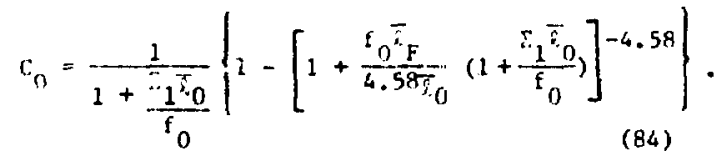

Tl: is is the Dancoff factor to he used in F.. (73). The non-collision probabilicy $\mathrm{p}_{\mathrm{nC}}$ of Eq. (70) can now bo related to $c_{n}$ because

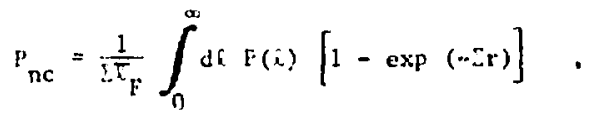

where $z_{1}$ is given by Eq. (RI).

Upon exaritination of Eqs. (81), (80), and (74), we can immediately conclude that

$$
P_{n c}-\frac{\bar{h}_{0}}{f_{0} \bar{l}_{F}} c_{0} \text {. }
$$

\section{c. Scattertng Effects in the Grains}

So far, any collisfon in the grain was tacitly assumed to result in abiorbtion. However, the grains used In HTGR's are chemical compounds with light elements and contain one or several light scattering atoms per absorber atom. It is, therefore, proper to replace $P_{e}$ in Eq. (63) by a multi.le crilision quantity $\mathrm{r}_{\mathrm{e}, \mathrm{s}}$ which accounts for multiple scatter1ngs tn the grains. The overall effect of this sutstitution on the corresponding absorber multigroup cross sections was seen to be significant although not very large, probably due to the relatively small size of the grains.
Let us first assume, ior simplicity, that the ratio of the scattering to totai cross section in the grain is energy independent. This restriction will be removed later. Then we can define an energyindependent scattering probabllity per collision in the grain as

$$
q=\frac{\Sigma_{s_{2} 0}}{\Sigma_{0}} \text {. }
$$

In view of this, we can further write the multiplecollision escape probabiltty from one grain as

$$
\begin{aligned}
P_{e, s} & =P_{e}\left[i+\left(1-F_{e}\right) q+\left(1-P_{e}\right]^{2} q^{2}+\ldots\right] \\
& =\frac{P e}{1-q\left(1-P_{e}\right)} .
\end{aligned}
$$

This expression was previously derived by Dyos and Ponraning ${ }^{8}$ and others. Substituring for $P_{e}$ from Eq. (1.4) in Eq. (87), we ottain

$$
p_{e, s}=\frac{1}{1+\frac{\sum_{a} \bar{l}_{0}}{a}} \text {, }
$$

where $\Sigma_{a}=\Sigma_{0}-\Sigma_{s, 0}$ is the macroscopic absorption cross secition in the grain.

The above restriction of $q$ being independent of energy implies that the scatterer is infinitely heavy so that no change in the neutron energy takes place through scattering. In the multigroup cross section approximation it is, therefore, reasonabie to replace $\sum_{s, 0}$ by : $s, 0$, the self-scattering cross section of the grcups (s) in willch resolved resonances fall. Hence, $P_{e, s}$ can be written as

$$
P_{e, s}=\frac{1}{1+\frac{\Sigma_{\text {out }, 00_{0}^{*}}}{a}} \text {, }
$$

where $\Sigma_{\text {out, } 0}$ is the out-scatter cross section in a particular group. Accordingly, one can now write

$$
P_{e, s}=\frac{1}{1+\frac{\ddot{E}_{0}^{T_{0}}}{a^{*}}} \text {, }
$$

where 


$$
a^{*}=\frac{a}{1-\frac{\Sigma_{s, 0}}{\Sigma_{0}}}
$$

Thus $a^{*}$ becomes energy dependent.

If one is interested in broad-group cross sections for use in transport calculations, all ${ }^{232} \mathrm{Th}$ resonances for an HTGR calculation are lumped in one or few groups. Quantity $\mathbf{a}^{*}$ then becomes a group constant and can still be used to replace a $f_{n} \mathrm{Eq}$. (33)

D. Application of the Method and Conclusions

The method discussed above was applied to the generation of few group cross sect? nns to be used for neutronics calculations of a large H'GR system. The results based on this method were compared with resulcs supplieì on magnetic tapes by General Atomic to Los Alamos Scientific Laboratory for the same reactor system and were calculated by the Gerieral Atomic code MICROX. ${ }^{4}$ They were also compared with LASI calculated cross sections based on the more elaborate grain shielding method of Wälti, apparently incorporated in the MICROX code. It should be pointed out that the Wält1 method operates on pointwise cross sections and its applicability depends upon accessibility to such cross section in a multigrouping code. At LASL, the wält grain shlelding method calculations were performed at the pointwise level by a specially witten code PEToPEs operating on PENDF cross sections (polntwise cross sections In ENDF/B format) gererated by the MLNY code. ${ }^{39}$ APplication of the new method discussed in this report does not require such sophistication and can be directly incorporated in most eplthermal collapsing codes, starting from fine-group cross sections. The code used at LASL was IDX (Ref, 33) which has the built-1n capability of accepting the Bondarenko formalism provided by the MINX code.

Detailed comparisons of results based on the various methods will be reported elsewhere. However, an fllustration of the quality of results obtalned with the method described in this report is given below.

Few group cross sections in an energy structure given In Table I were calculated at several temperatures by the above method and by the wäli grain shielding method. Also, resuits from General Atomic, calcuiated with the MICROX code, were provided t? LASL for the same reactor system and the same fewgroup energy structure. A11 ${ }^{232}$ Th resolved resonances in this energy structure are incorporated in above-thermal group 3 having boundarles at 96.0 and $17.6 \mathrm{eV}$. Table II shows a compartson of the ${ }^{232} \mathrm{Th}$ group 3 ausorption (capture) cross sections for three temperatures, 300,800 , and $1200^{\circ} \mathrm{K}$, as calculated by MTNX and IDX incorporating the present method (P.M.), as calculated by MINX (including the Walti pointwise grain shielding method) and $1 D X$ (MINX/1DX), and as supplied by General Atomic (MICROX). Methods I and II used basic ENDF/B-III cross sections as initial input data.

TABIAE I

FEW-GROUP EPITHERMAL ENERCY STRUCTURE

\begin{tabular}{cl} 
Group No & Energy Boundaries \\
\cline { 1 - 2 } & $10 \mathrm{MeV}-183 \mathrm{keV}$ \\
2 & $183 \mathrm{keV}-961 \mathrm{eV}$ \\
3 & $961 \mathrm{eV}-17.6 \mathrm{eV}$ \\
4 & $17.6 \mathrm{eV}-3.95 \mathrm{eV}$ \\
5 & $3.95 \mathrm{eV}-2.38 \mathrm{eV}$ \\
6 & $2.38 \mathrm{eV}-0.414 \mathrm{eV}$
\end{tabular}

TABLE II

RESOLVED-RESONANCE-GROUP ABSORPTION CROSS SECTION IN ${ }^{232}$ Th (barns)

\begin{tabular}{|c|c|c|c|}
\hline $\begin{array}{l}\text { Temper- } \\
\text { ature } \\
\left({ }^{\circ} \mathrm{K}\right)\end{array}$ & $\begin{array}{l}\text { Method I } \\
M(P . M .)\end{array}$ & $\begin{array}{l}\text { Method II } \\
\text { (MINX/1DX) }\end{array}$ & $\begin{array}{l}\text { Method III } \\
\text { (MICROX) }\end{array}$ \\
\hline $\begin{array}{r}300 \\
800 \\
1200\end{array}$ & $\begin{array}{l}6.64 \\
7.94 \\
8.56\end{array}$ & $\begin{array}{l}6.58 \\
7.82 \\
8.42\end{array}$ & $\begin{array}{l}6.76 \\
8.12 \\
8.78\end{array}$ \\
\hline
\end{tabular}

\section{ACKNOWLEDGMENTS}

The author is grateful to R. J. LaBauve of Los Alamos Scientific Laboratory Group $\mathrm{T}-2$, and to $\mathrm{M}$. Becker of the Rensselaer Polytechnic Institute for many illuminating discussions on the subject of this report. Many thanks are due to R. J. LaBauve, P. G. Young, and D. R. Harris of Los Aiamos Scjentific Laboratory Group $\mathrm{T}-2$, and to J. Vigil of Los Mlamos Scientific Laboratory Group T-1 for continuous encouragement and support throughout this work.

\section{REFERENCES}

1. C. A. Stevens and C. V. Smith, "GAROL, A Computer Program for Evaluating Resonance Absorption Including Resonance Overlap, "General Atomic report GA-6637 (1965). 
2. D. R. Mathews, P. K. Koch, J. Adir and F. Wälti, "GGC-5, A Computer Program for Calculating Neutron Spectra and Group Constants," Gulf General atomic report GA-8871 (1971).

3. P. Wälti, "Evaluation of Grain Shielding Factors for Coated Fuel Particles," Nu:1. Sci. \& Engr. 45, 321 (:971).

4. P. Wälti and P. Koch, "MICRoX, A Two-Region Flux Spectrum Code for the Efficient Calculation of Group Cross Sections," Gulf General Atomic report GA Al0827 (1972).

5. W. B. Doub, "Particle Self-Shielding in Plates Loaded with Spherical Poison Particles," Nuc1. Sci.\& Engr. 10, 299 (1961).

6. R. K. Lane, L. W. Nordheim and J. B. Sampson, "Resonance Absorption in Materials with Grain Structure," Nucl. Sc1. \& Engr. 14, 390 (1962).

7. W. R. Burrus, "Radiation Transmission Through Borax and Simflar Heterogeneous Materials Consisting of Randomly Distributed Absorbing Chunks," Oak Ridge National Laboratory report ORNL--2528 (1960).

8. M. W. Dyos and G. C. Pomraning, "Effective Thermal-Neutron Cross Section for Materials with Grain Structure," Nuc1. Sci. \& Engr. 25, $8(1966)$.

9. V. Hansen and E. Teuchert, "lufluence of Coated-Particle Structure in Therma1-NeutronSpectrum Energy Range," Nucl. Sci. Engr. 44, 12 (1971).

10. J. R. Askew and G. M. Carpenter, "Resonance Capture in Plutonium-240 Part III: Plutonium Carbide Particles in a Graphite Matr 1x," United Kingdom Atomic Energy Authority report AEEW-M236 (1969).

11. C. L. Bennett, "GranIT: A Code for Calculating Position Dependent Thermal Neutror Spectra in Doubly lic: - : ogeneous Systems by the Integral Transport Method," Battelle Pacif ic Northwest Laboratory report BNWL-1634 (1971).

12. A. Keane, "Equivalence Relations for Resonance Absorption in Small Particles," Australian Atomic Energy Comission repert AAEC/T120 (1964).

13. H. Mizuta, K. Aoyama and Y. Fukai, "RICM An IBM-7090 Code of Resonance Integral Calculation for Multi-region Lattice," Japan Atomic Energy Research Institute report JAERI-1134 (1967).

14. G. F. Kuncir, "A Program for the Calculation of Resonance Integrals," General Atomic report GA-2525 (1961).

15. G. L. Ragan, 0. L. Smith and N. M. Greene, "Estimates of Resonance Self-Shlelding Effects In Doubly Heterogeneous Systems," Trans. Am. Nucl. Soc. 15, 453 (1972).
16. E. Teuchert, "Resonanzabsorption in einer 2 k'eifach heterogenen Anordnung Kugelförmiger Brennelemente," Nukleonik 11, 68 (1968).

17. H. Jonas, R. Heck ar and M. Kloth, "Grain Structure of High Temperature Gas-Cooled Reactor Fuel and its Influence on the Effective Resonance Integral," Nucl. Sci. \& Engr. 58, 89 (1975).

18. K. Tsuchihashi and Y, Gotoh, "The Resonance Integral of Cuated Particles," Nucl. Sc1. \& Engr. 58, 213 (1975).

19. R. A. Lewis and T. J. Connolly, "Resonanre Absorption in Particles," Nurl. Sci. \& Engr. 24, 18 (1966).

20. G. I. Bell and S. Glasstone, Nuclear Reactor Theory (Van Nostrand Reinhold Company, New York, 1970).

21. K. M Jase, F. DeHoffman and G. Plarzek, Ints: uction to the Theory of Neutron Diffusion (U.S. Government Printing office, Washingcon, D.C. 1953).

22. I. Carlvik and B. Pershagen, "The Dancoff Correction In Various Geomerries," Aktiebolaget Atomenergi report $\mathrm{AE}-16$ (1959).

23. I. Carlvik, "Dancoff Correction in Square and Hexagonal Lattices," Aktiebolaget Atomenergi report AE-257 (1966).

24. E. P. Wigner, E. Creutz, H. Jupnik and T. Snyder, "Resonance Absorption of Neutrons by Spheres," J. of Appl. Phys, 26, 260 (1955).

25. G. I. Bell, "A Simple Treatment for Effective Resonance Absorption Cross Sections in Dense Lattices," Nucl. Sci. \& Engr. 5, 138 (1959).

26. G. I. Bell, "Theory of Effective Cross Sections," Los Alamos Sclentific Laboratory report LA-2322 (1959).

27. M. M. Levine, "Resonance Integral Calculations

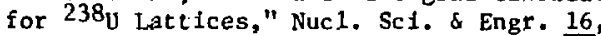
271 (1963).

28. J. M. Otter, "Escape Probability Appcoximations in Lumped Resonance Absorbers," Atomics International report NAA-SR-9744 (1964).

29. C. N. Kelber, "Improved Rational Escape Probability in Lumped Absorbers," Nucl. Sct. \& Engr. 22, 244 (1965).

30. C. N. Kelber, "An Extended Equivalence Relation," Nucl. Sci. \& Engr. 42, 257 (1970).

31. D. C. Leslie, J. G. H111 and A. Jonsson, "Improvements to the Theory of Resonance Escape in Heterogeneous Fuel," Nuc1, Sci.\& Engr. 22, 78 (1965).

32. B. J. Toppel, A. L. Rago and D. M. O'Shea, "MC ${ }^{2}$, A Code to Calculate Multigroup Cross Sections," Argonne National Laboratory report ANL-7318 (1967). 
33. R. W. Hardie and W. W. Little, Jr, , "1DX, A One-Dimensional Diffusion Code for Generating Effective Nuclear Cross Sections, "Battelle Northwest Laboratory report BNWL-954 (1969).

34. L. Dresner, Resonance Absorption in Nuc lear Reactors (Pergamon Press, New York, 1960).

35. I. I. Bondarenko, ed., Group Canstants for Nuclear Reactor Calculations (Consultants Bureau, New York, 1964).

36. B. R. Sehgal and R. Goldstein, "Intermedlate Resonance Absorption in Heterogeneous Media," Nuc I. Sci. \& Engr. 25, 174 (1966).
37. B. R. Sehgal, "Resonance Absorption for Heavy Moderacors ini Homogeneous Hedia," J. of Nucl. Energy A/B 19, 921 (1965).

38. A. Sauer, "Approximate Escape Probabilities," Nuc1. Sci. \& Engr. 16, 329 (1963).

39. C. R. Weishin, P. D. Soran, D. R, Harris, R. $J$. LaBauve and J. S. Hendricks, "MINX, A Multi-group Interpretation of Nuclear XSections," lrans, Am. Nucl, Soc, 16, 127 (1973). 